\title{
Computational fluid dynamics study of flow depth in an open Venturi channel for Newtonian fluid
}

\author{
Prasanna Welahettige ${ }^{1}$, Bernt Lie ${ }^{1}$, Knut Vaagsaether ${ }^{1}$ \\ ${ }^{1}$ Department of Process, Energy and Environmental Technology \\ University College of Southeast Norway \\ Porsgrunn, Norway \\ knut.vagsathereusn. no
}

\begin{abstract}
Open Venturi channel flow measurement could be a cheap method to be used in drill bit pressure control. The main objective of this study is to identify the factors related with the flow depth in an open Venturi channel. A commercial computational fluid dynamics tool was used for the simulations. The simulation results were validated with the previous related experimental results. The agreement between simulation and experimental data was satisfactory. The open Venturi channel at a horizontal angle gave a higher flow depth before the contraction region compared to its negative angles (downward). When the channel inclination angle was reduced, flow velocity increased and flow depth reduced. Likewise, flow became supercritical and created a hydraulic jump. The wall roughness played a significant role with the starting position of the hydraulic jump. This was due to the energy loss between wall and fluid. There is an energy loss in a hydraulic jump, when the supercritical flow transition into the subcritical flow. Large eddies were generated in a hydraulic jump. Flow depths difference between supercritical and subcritical is a factor to generate the large eddies. Fine meshes gave sharp interfaces, which was similar to what is seen in reality. The difference turbulence models: standard k- $\varepsilon$ model, $\mathrm{k}-\omega$ model, $\mathrm{k}-\varepsilon$ RNG model and k- $\varepsilon$ realizable model gave almost the same flow depths.
\end{abstract}

Keywords: $\quad$ Flow depth, velocity, open Venturi channel, hydraulic jump, energy loss

\section{Introduction}

Hydraulic jumps generate due to transition of the supercritical flow into the subcritical flow in an open Venturi channel (Welahettige et al., 2017). In a hydraulic jump, a strong shear layer is formed at the toe of the wave (Hornung et al., 1995). The resistance phenomena in an open channel can be explained by using the inner and outer layer theory (Ben, 2002). A constant value for the roughness coefficient is not recommended for an open channel flow (Konwar \& Sarma, 2015). The Colebrook White explicit equation is comparatively suitable for friction handling about the unsteady varied flow and the tidal computations in an open channel (Ahmed, 2015). The level jump in a
Venturi channel depends upon the fluid properties and the length of the flume (Berg et al., 2015). There are few studies on flow depth parameters related to the open Venturi channel in literature. This study focused on the flow depth variation in an open Venturi channel for Newtonian fluid. Computational fluid dynamics (CFD) simulations were validated with experimental results (Welahettige et al., 2017). ANSYS Fluent R16.2 commercial simulation tool was used for the simulations.

\section{CFD models}

The Volume of fluid (VOF) method was used for the simulations where phase interaction was based on the continuum surface force model and the phase localize compressive scheme (ANSYS, 2013). Equation. 1 gives the species mass balance. Here, $\alpha_{2}$ is the water volume fraction, $U$ is the three-dimensional velocity component, and $U_{r}$ is the maximum velocity at the transition region. $\alpha_{2}\left(1-\alpha_{2}\right)$ is non zero only at the interface (Rusche, 2002), (Weller et al., 1998) and (Ubbink, 1997).

$$
\frac{\partial \alpha_{2}}{\partial t}+\operatorname{div}\left(\alpha_{2} U\right)=-\operatorname{div}\left(\alpha_{2}\left(1-\alpha_{2}\right) U_{r}\right)
$$

The normalized wall roughness $\left(K_{s}^{+}\right)$is given as, (ANSYS, 2013), (Akan, 2006) and (Versteeg \& Malalasekera, 2007):

$$
\begin{aligned}
& K_{s}^{+}=\rho \mathrm{K}_{s} \mathrm{u}^{*} / \mu . \\
& \mathrm{u}^{*}=C_{\mu}^{1 / 4} \kappa^{1 / 2}
\end{aligned}
$$

Here, $\mathrm{K}_{s}$ is the physical roughness. $\mathrm{u}^{*}$ is a constant equal to 0.346 . Here $C_{\mu}=0.09$ is a k- $\varepsilon$ model constant and $\kappa=0.4$ is the von Karman's constant. Density $(\rho)$ and viscosity $(\mu)$ are considered as,

$$
\begin{aligned}
& \rho=\alpha_{2} \rho_{2}+\left(1-\alpha_{2}\right) \rho_{1} \\
& \mu=\alpha_{2} \mu_{2}+\left(1-\alpha_{2}\right) \mu_{1} .
\end{aligned}
$$


Here, $\rho_{1}$ and $\rho_{2}$ are the densities of air and water. $\mu_{1}$ and $\mu_{2}$ are the viscosities of air and water.

Time discretization was based on the implicit Euler method for transient simulations. The semi implicit method for pressure linked equations (SIMPLE) scheme was used to calculate the pressure-velocity coupling. The hyperbolic partial differential equations were solved by using the second order upwind scheme (Versteeg \& Malalasekera, 2007) and (ANSYS, 2013).

\section{Geometry}

Figure 1 shows a 3-D geometry that was used for the simulations. Boundaries were inlet, outlet, wall, and atmosphere. $X$-direction was the main flow direction, from the inlet to the outlet. The channel width was in $Y$ direction. The flow depth was measured in $Z$-direction. The main mesh contained 0.74 million computational cells. The elements near to the wall boundaries were modified by adding inflation layers.

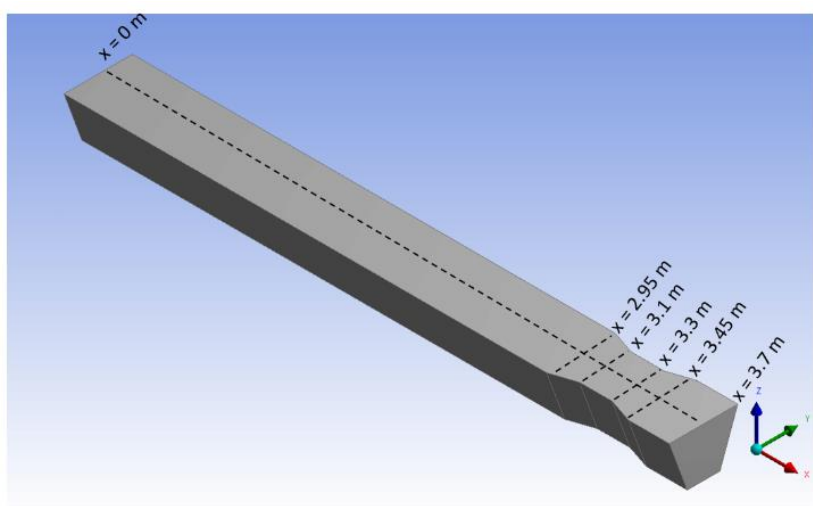

Figure 1. 3-D geometry of the trapezoidal channel; $x=$ $0 \mathrm{~m}$ was defined as the inlet of the channel. The Venturi region was $x=2.95 \mathrm{~m}$ to $x=3.45 \mathrm{~m}$. The bottom depth was $0.2 \mathrm{~m}$ for $0 \mathrm{~m}<x<2.95 \mathrm{~m}$ and $3.45 \mathrm{~m}<x<3.7$ $\mathrm{m}$. The bottom depth was $0.1 \mathrm{~m}$ for $3.1 \mathrm{~m}<x<3.3 \mathrm{~m}$. The trapezoidal angle was $70^{\circ}$.

\section{Results and discussion}

\subsection{Flowrate and flow depth}

Figure 2 shows flow depths along the channel central axis for different flow rates. The channel inclination angle was zero degrees (horizontal) for all the cases in Figure 2. Simulations were done for water the flow rates: $100 \mathrm{~kg} / \mathrm{min}, 200 \mathrm{~kg} / \mathrm{min}, 300 \mathrm{~kg} / \mathrm{min}, 400 \mathrm{~kg} / \mathrm{min}$ and $700 \mathrm{~kg} / \mathrm{min}$. The experimental water flow rate result, which was equal to $400 \mathrm{~kg} / \mathrm{min}$, was used for the validation (Welahettige et al., 2017). The contraction region started at $x=2.95 \mathrm{~m}$ (see Figure 1). The flow depth increased with increased of the flow rate. The flow depth increment with the flow rates was not a linear relationship due to the geometry of the channel. Flow depth near to the contraction walls slightly increased in high flow rates (e.g. $700 \mathrm{~kg} / \mathrm{min}$ ). Low flow rates showed almost horizontal flow depths until the Venturi contraction walls (e.g. $200 \mathrm{~kg} / \mathrm{min}$ ). The flow depth was reduced from the end of the Venturi contraction to the outlet of the channel for all the cases. There were no barriers at the end of the channel and the channel expanded after the contraction. Therefore, flow condition was changed from subcritical to supercritical, when flow depth reduced at the end of the channel (Welahettige et al., 2017). In generally, the channel at horizontal angle gives subcritical flow before the contraction and supercritical flow after the contraction for all flow rates. The flow transition from subcritical to supercritical occurs at the Venturi region for all flow rates (when the channel at horizontal angle).

Figure 3 shows the average velocities along the $\mathrm{x}$-axis for different flow rates. The average water velocity was calculated by considering the average of all cell's velocities in the considered cross section (except air velocities in the cross section). Velocities before the contraction region were averagely constant in each cases. This was due to the constant flow depths in this region (see Figure 2). Velocity gradually increased after the Venturi region due to the flow depth reduction. According to Bernoulli's law, the potential energy converts into the kinetic energy in this region. Mass flow rate $(\dot{m})$ is given as

$$
\dot{m}=\rho h\left(b+\frac{h}{\tan \theta}\right) \bar{U} .
$$

Here, $b$ is the bottom width, $\theta$ is the trapezoidal angle, $\rho$ is the density of water. Flow depth $(h)$ and the average velocity perpendicular to the area $(\bar{U})$ are variables with the mass flow rate for a considered position. When the mass flow rate increases, both flow depth and flow velocity increase in the channel. Because of this, the high mass rates give higher flow depths and higher flow velocities compared to the low mass flow rates.

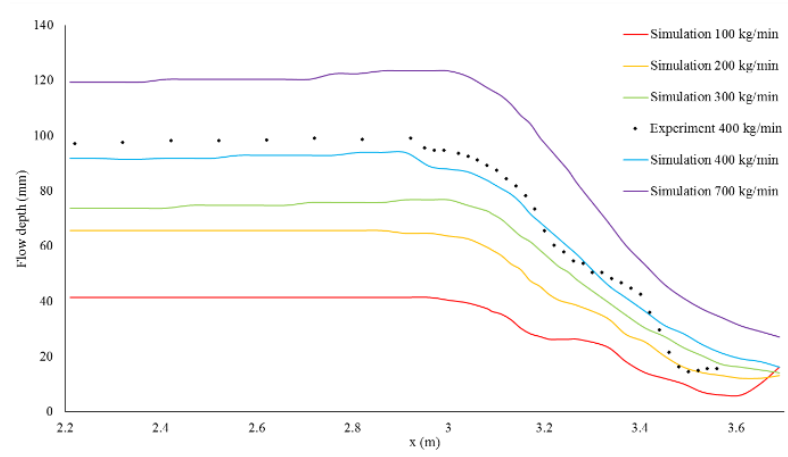

Figure 2. Flow depth changes along the channel centerline axis in the Venturi region for different flow rates. The channel inclination angle was zero degrees. The 
experimental result was from (Welahettige et al., 2017) for $400 \mathrm{~kg} / \mathrm{min}$ water flow rate.

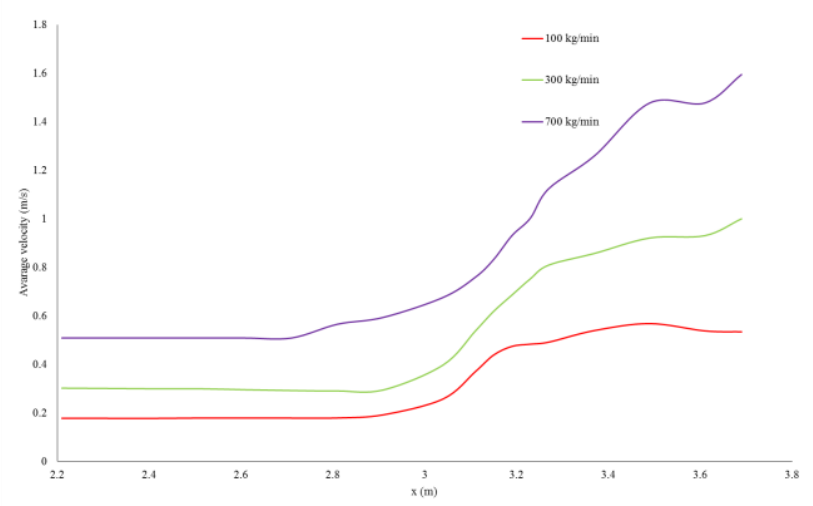

Figure 3. The average velocity along the $x$-axis for different water flow rates. The channel inclination angle was zero degrees for all cases. The average velocity was calculated as the average cross sectional velocity perpendicular to $\mathrm{x}$-axis.

\subsection{Different channel inclination angles and flow depths}

Figure 4 shows the flow depth variation with the channel inclination angles. In this case, flow rate was $400 \mathrm{~kg} / \mathrm{min}$ for all the cases. When the channel inclination angle was a negative value, a gravitational support added to the flow direction (x-direction). When the channel inclination angle was a positive value, a gravitational support added opposite to the flow direction. The highest flow depth was given before the Venturi contraction, when the channel inclination angle was +1.5 degree. In this region, flow became subcritical due to the barriers such that the contraction walls and the gravitation opposite force (only in the positive channel inclination cases). The channel at the horizontal angle, the flow depth was almost a flat surface. Because only the contraction walls hydraulic jumps were affected opposite to the flow direction, except the friction force. When the channel inclination angle was a negative value, the flow depth before the Venturi contraction reduced due to flow convert into the supercritical flow (Welahettige et al., 2017). At -1.0 degree angle, the flow depth increased in the Venturi region due to the oblique jump propagation (Welahettige et al., 2017). There was a level fluctuation in -0.7 degree angle case at $x=2.2$ $\mathrm{m}$. This was due to the hydraulic jump propagation. The flow depths after the Venturi showed almost equal values for all the angles because of all the cases reached to the supercritical flow condition at the end of the channel.

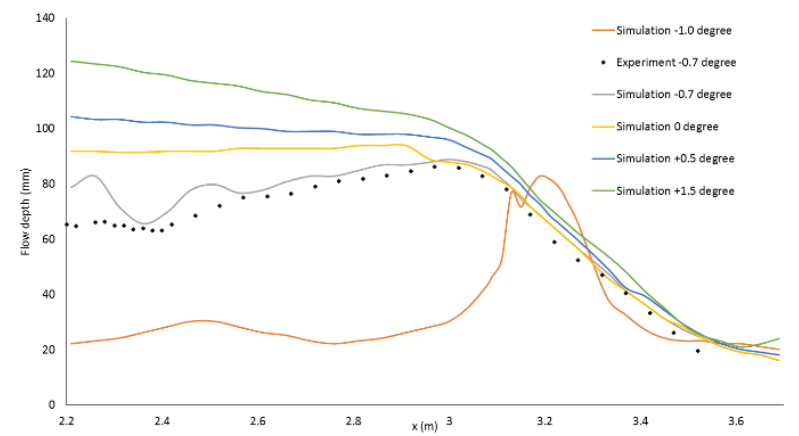

Figure 4. Flow depth change along the $\mathrm{x}$-axis due to variation of channel inclination angles. The water flow rate was $400 \mathrm{~kg} / \mathrm{min}$. Flow depth was measured along the channel central axis. The experimental result was taken from (Welahettige et al., 2017).

Figure 5 gives the average flow velocity for different inclination angles, the water flow rate at $400 \mathrm{~kg} / \mathrm{min}$. the high velocities for the negative inclination showed due to the supercritical flow behavior. There was a large difference of velocities between -1 degree case and horizontal case before the Venturi contraction. Even before the contraction walls; the flow reached to the supercritical condition in the negative inclination cases. However, there was no significant velocity difference after the contraction region in these cases. This was due to the fluid convert into the supercritical and the flow depths were averagely equal in all the cases.

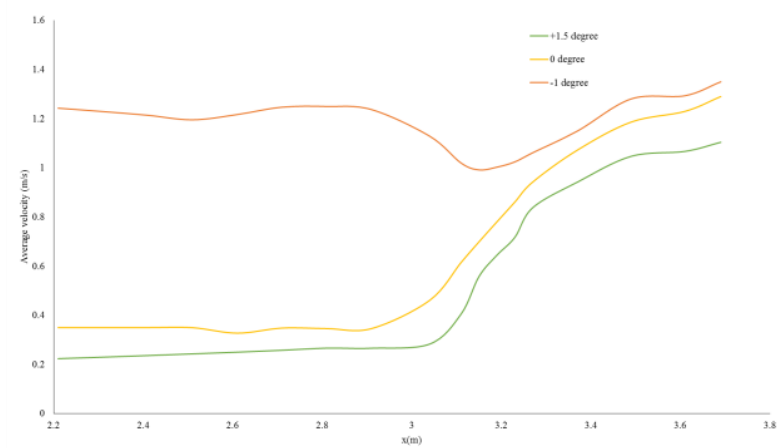

Figure 5. The average velocity along the $x$-axis for different channel inclination angles. The water flow rate was $400 \mathrm{~kg} / \mathrm{min}$.

\subsection{Wall roughness height effect on flow depth}

The wall roughness height related with wall friction and heat losses (ANSYS, 2013). Figure 6 shows the steady state water volume fraction for different the wall roughness values. The water flow rate was $400 \mathrm{~kg} / \mathrm{min}$ and the channel at horizontal angle for all the cases. When the wall roughness height was increased, a hydraulic jump was generated before the Venturi region. In other words, toe of the hydraulic jump was moved to the upstream direction. This was due to increase of energy loss from the walls, when increased the wall roughness height. When energy loss increased, it could 
not continue as a supercritical flow. Therefore, hydraulic jump moved to the upstream. Wall roughness height $0.000015 \mathrm{~m}$ was given a good matching with the experiment results.

\section{L}

(a)

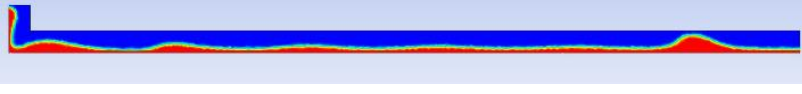

(b)

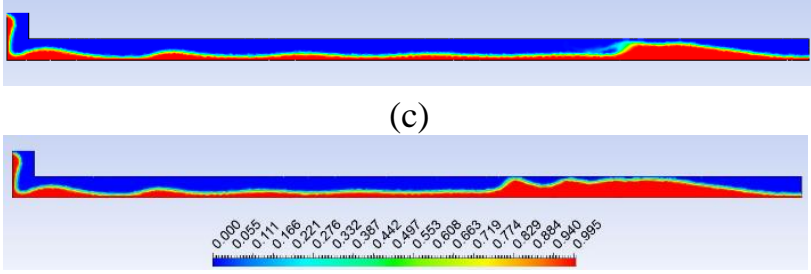

(d)

Figure 6. Steady state water volume fraction comparison for different wall roughness height. Water flow rate was $400 \mathrm{~kg} / \mathrm{min}$ and the channel inclination angle was zero degrees; (a) Wall roughness height $=0 \mathrm{~m}$, (b) Wall roughness height $=0.000015 \mathrm{~m}$, (c) Wall roughness height $=0.0001 \mathrm{~m},(\mathrm{~d}) \mathrm{Wall}$ roughness height $=0.001 \mathrm{~m}$.

\subsection{Velocity distribution}

The case with the flow rate $300 \mathrm{~kg} / \mathrm{min}$ and the inclination angle zero degrees was used for the velocity distribution analysis. The average Reynolds number was approximately 46000 and the flow was averagely turbulent. Air velocity was approximately zero above the water surface except at the interface. The VOF model solves a single momentum equation. Therefore, the interface has a same velocity for air and water. The water velocity at the wall was zero due to the no-slip boundary condition. Figure 7 shows water velocity magnitudes along the z-axis: before the Venturi contraction $(x=2.51 \mathrm{~m})$, at the middle of Venturi $(x=3.19 \mathrm{~m})$ and after the expansion of the Venturi $(x=3.61 \mathrm{~m})$. The velocity distribution before the contraction walls were lower value compared to the other two locations because subcritical flow gave high flow depths and low velocities. The velocity increased from the bottom to the top in all the cases. This was due to the gradually reduction of friction from the bottom to the top.

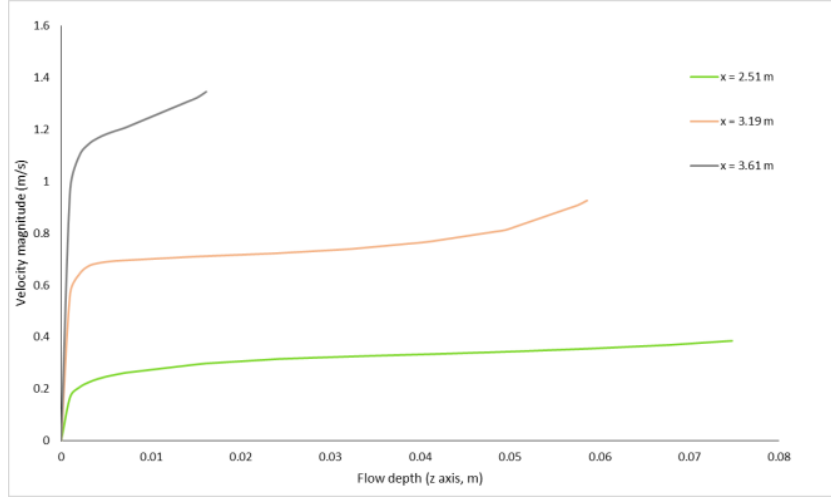

Figure 7. Water velocity magnitude along the vertical central lines in different location of the Venturi region; at $\mathrm{x}=2.51 \mathrm{~m}$ (before the Venturi contraction), $\mathrm{x}=3.19 \mathrm{~m}$ (at the middle of the Venturi), $x=3.61 \mathrm{~m}$ (after the Venturi expantion); The water flow rate was $300 \mathrm{~kg} / \mathrm{min}$ and the channel inclination angle was zero degrees.

\subsection{Mesh dependency evaluation}

The mesh dependency evaluation was done with following meshes shown in Table 1. Total number of elements in a mesh was increased by reducing the maximum face size of cells.

Table 1. Mesh details for mesh dependency analysis: total number of elements and maximum face size

\begin{tabular}{|l|l|l|}
\hline & Total number of elements & Maximum face size (mm) \\
\hline 01. & 16815 & 20 \\
\hline 02. & 23217 & 15 \\
\hline 03. & 61464 & 10 \\
\hline 04. & 104910 & 8 \\
\hline 05. & 378635 & 5 \\
\hline 06. & 1598267 & 3 \\
\hline
\end{tabular}

Figure 9 shows water volume fraction along the z-axis at $x=3.19 \mathrm{~m}$ for the different meshes. The coarse meshes $(20 \mathrm{~mm}$ and $15 \mathrm{~mm})$ gave wide range of interface variations. However, the fine meshes give sharp interfaces. In reality, there is very sharp interface between water and air. Therefore, the finer meshes gave more accurate results than the coarser meshes. This implies that mesh size is a critical factor for VOF simulations. It is recommended to have a fine mesh for small flow depths. 


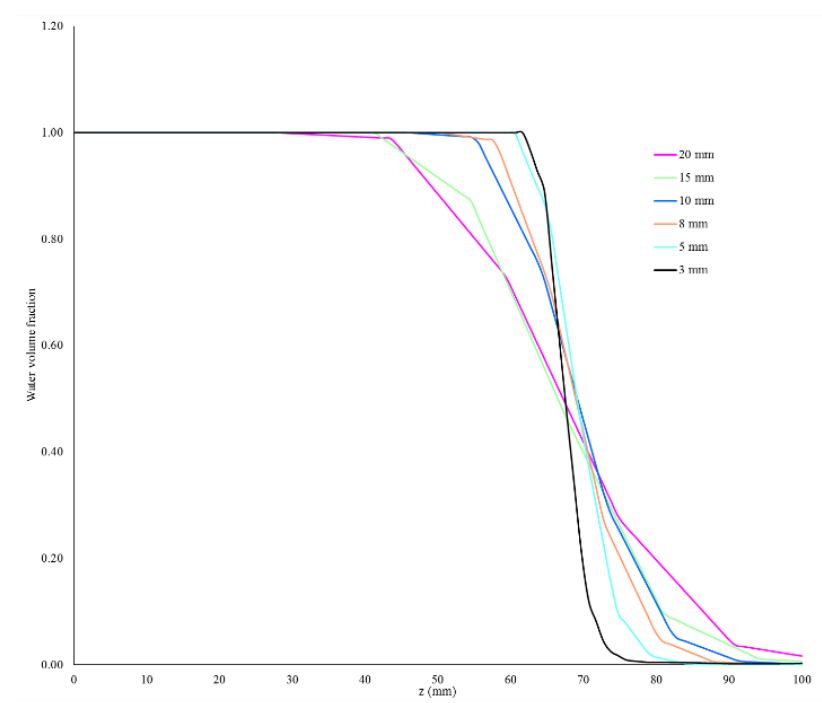

Figure 8. Mesh dependency analysis: The maximum cell face sizes in the meshes $20 \mathrm{~mm}, 15 \mathrm{~mm}, 10 \mathrm{~mm}, 8 \mathrm{~mm}, 5$ $\mathrm{mm}$ and $3 \mathrm{~mm}$ : Water volume fraction along z-axis at $\boldsymbol{x}=$ $3.19 \mathrm{~m}$.

\subsection{Effect of turbulence models on flow depth}

Figure 7 shows water volume fraction along the y-axis for different turbulence models at $x=3.19 \mathrm{~m}$. There was no significant effect for the flow depth from different turbulence models: standard k- $\varepsilon$ model, $\mathrm{k}-\omega$ model, $\mathrm{k}-\varepsilon$ RNG model and $\mathrm{k}-\varepsilon$ realizable model. At the steady state, all the turbulence models gave similar results. However, the standard $\mathrm{k}-\varepsilon$ model took higher computational time compared to the other turbulence models.

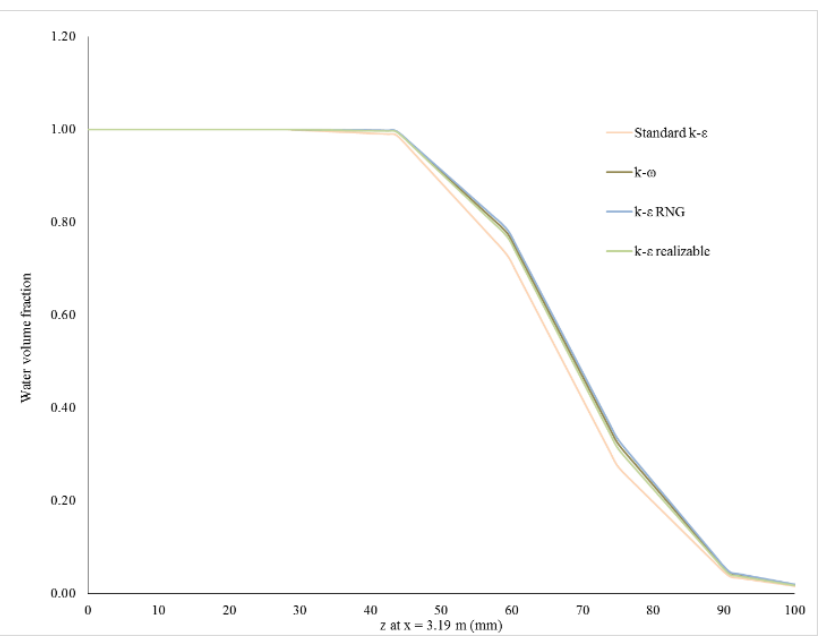

Figure 9. Water volume fraction along the z-axis at $\boldsymbol{x}=$ $3.19 \mathrm{~m}$ for different turbulence model: Standard $\mathrm{k}-\varepsilon$ model, $\mathrm{k}-\omega$ model, $\mathrm{k}-\varepsilon$ RNG model and $\mathrm{k}-\varepsilon$ realizable model.

\subsection{Energy loss in a hydraulic jump}

Figure 10 shows a hydraulic jump. There were large eddies propagation in a hydraulic jump. Hydraulic jump was very unstable due to the higher turbulence (Xiang et al., 2014). A short and fine domain mesh (3 $\mathrm{mm}$ mesh in mesh dependency test) was used for the energy calculation. The flow rate was $400 \mathrm{~kg} / \mathrm{min}$ and the channel inclination angle was -1.5 degree.

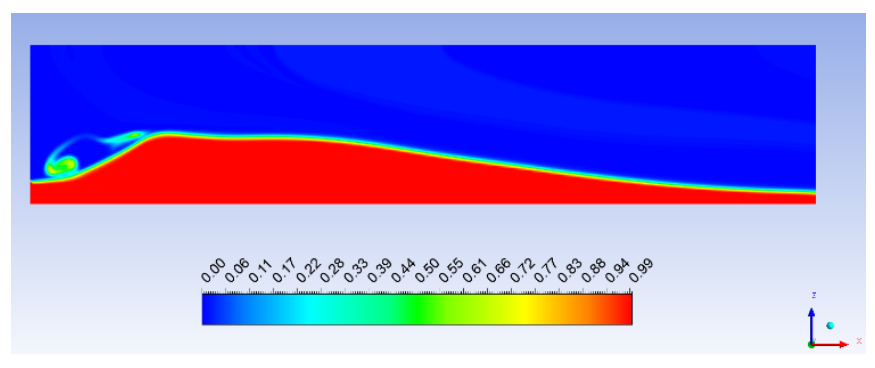

(a)

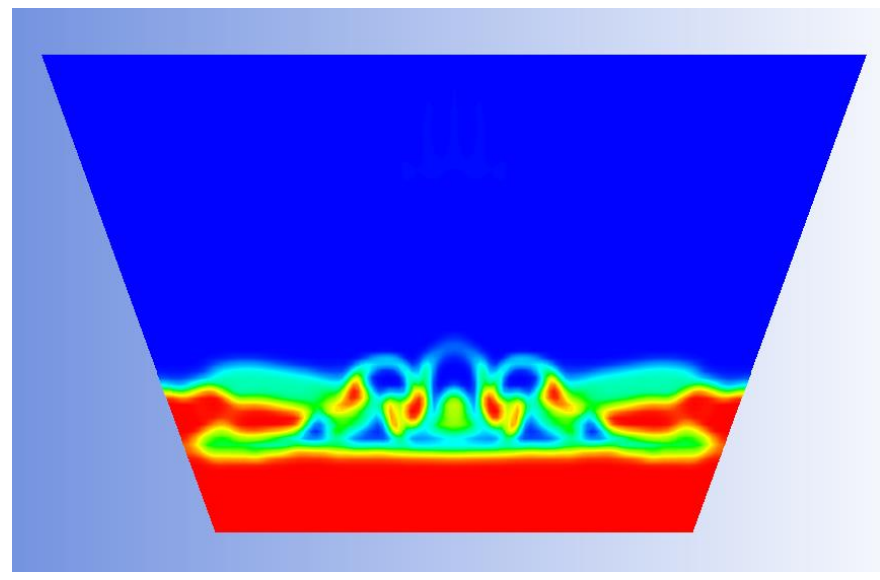

(b)

Figure 10. Water volume fraction of a hydraulic jump, (a) Central axis plane, (b) Channel cross sectional view at a hydraulic jump

The specific energy head $\left(E_{S}\right)$ at a point can be given as the sum of the potential energy and the kinetic energy for 1-D system.

$$
E_{s, 1-D}=h+h_{h s}+\frac{\bar{U}^{2}}{2 g}
$$

Here, $h$ is the flow depth, $h_{h s}$ is the hydrostatic head, and $\bar{U}$ is the average flow velocity. The potential energy head was a sum of the flow depth and the hydrostatic head. The gravity point of the flow depth was assumed at the half of the flow depth. The specific energy difference before and after the hydraulic jump was due to the energy loss. The hydraulic jump approximately was in $x=2.7 \mathrm{~m}$ to $x=2.85 \mathrm{~m}$. Specific energy head, kinetic energy head and potential energy head is shown in Figure 11. When the flow depth increased, the kinetic energy reduced in the hydraulic jump. The kinetic energy was predominant before started the hydraulic jump. Then it was drastically reduced in the hydraulic jump. This was due to the main flow kinetic energy participated to increase the turbulence kinetic energy. There was a head loss in the hydraulic jump, which was approximately $0.47 \mathrm{~m}$ in this case. The head 
loss was due to the turbulence eddies finally converted into the internal energy.

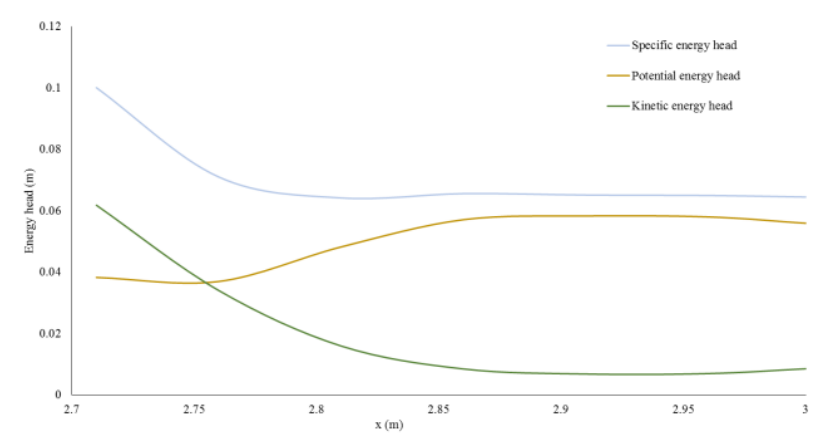

Figure 11. Energy loss in a hydraulic jump: specific energy head, potential energy head, and kinetic energy head.

This research study will be further extended into oil well drill mudflow analysis in an open Venturi channel.

\section{Conclusions}

The open Venturi channel at the horizontal angle gives a high flow depth before the contraction region. When the channel inclination angle is downward, the flow velocity increases and flow depth reduces. Because of this, flow becomes supercritical. The wall roughness height plays a significant role with the starting point of a hydraulic jump, due to the energy loss between wall and fluid. There is an energy loss in a hydraulic jump, when the supercritical flow transition into the subcritical flow. Fine mesh gives a sharp interface, which is similar with the reality. Turbulence models: Standard k- $\varepsilon$ model, k- $\omega$ model, $\mathrm{k}-\varepsilon$ RNG model and k- $\varepsilon$ realizable model give almost similar flow depths. However, standard k- $\varepsilon$ model was taken higher computational time compared to the other models.

\section{Acknowledgment}

The economic support from The Research Council of Norway and Statoil ASA through project no. 255348/E30 "Sensors and models for improved kick/loss detection in drilling (Semi-kidd)" is gratefully acknowledged. As well as authors acknowledge to University College of Southeast Norway for giving resources for simulations.

\section{References}

Ahmed Z. (2015). Review of friction formulae in open channel flow Paper presented at the Eighteenth International Water Technology Conference, IWTC18

Akan O. (2006). Open Channel Hydraulics. Oxford: ButterworthHeinemann.

ANSYS I. (2013). ANSYS Fluent Theory Guide.

Ben C. (2002). Open Channel Flow Resistance. Journal of

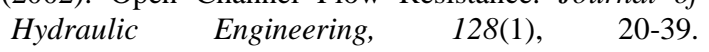
doi:doi:10.1061/(ASCE)0733-9429(2002)128:1(20)
Berg C., Malagalage A., Agu C., Kaasa G., Vaagsaether K. and Lie B. (2015). Model-based drilling fluid flow rate estimation using Venturi flume. IFAC Workshop on Automatic Control in Offshore Oil and Gas Production, 2, 177-182.

Hornung H., Willert C. and Turner S. (1995). The flow field downstream of a hydraulic jump. Journal of Fluid Mechanics, 287, 299-316. doi:10.1017/S0022112095000966

Konwar L. and Sarma B. (2015). Analysis and Verification of Resistance Co-Efficient with Different Flow Parameters Having Different Bed Conditions to Open Channel Flow. International Advanced Research Journal in Science, Engineering and Technology, 2(8), 106-110.

Rusche H. (2002). Computational Fluid Dynamics of Dispersed Two-Phase Flows at High Phase Fractions. (Doctor of Philosophy), University of London Exhibition Road, London.

Ubbink O. (1997). Numerical prediction of two fluid systems with sharp interfaces. (Degree of Doctor of Philosophy), Imperial College of Science, Technology \& Medicine.

Versteeg H. and Malalasekera W. (2007). An introduction to computational fluid dynamics: The finite volume method (2 ed.). Harlow, England: Pearson Education.

Welahettige P., Lie B. and Vaagsaether K. (2017). Flow regime changes at hydraulic jumps in an open Venturi channel for Newtonian fluid. The journal of computational multiphase flow, Accepted.

Weller H., Tabor G., Jasak H. and Fureby C. (1998). A tensorial approach to computational continuum mechanics using object-oriented techniques. Computers in Physics, $12(6)$, 620-631. doi:http://dx.doi.org/10.1063/1.168744

Xiang M., Cheung S. C. P., Tu J. Y. and Zhang W. H. (2014). A multi-fluid modelling approach for the air entrainment and internal bubbly flow region in hydraulic jumps. Ocean Engineering, 91, 51-63. doi:https://doi.org/10.1016/j.oceaneng.2014.08.016 